\title{
科学史与科学家介紹
}

\section{衰悼偉大的科学家与和平战士 伊倫・約里奥一居里}

\author{
楊承宗
}

（中国科学院物理明究所）

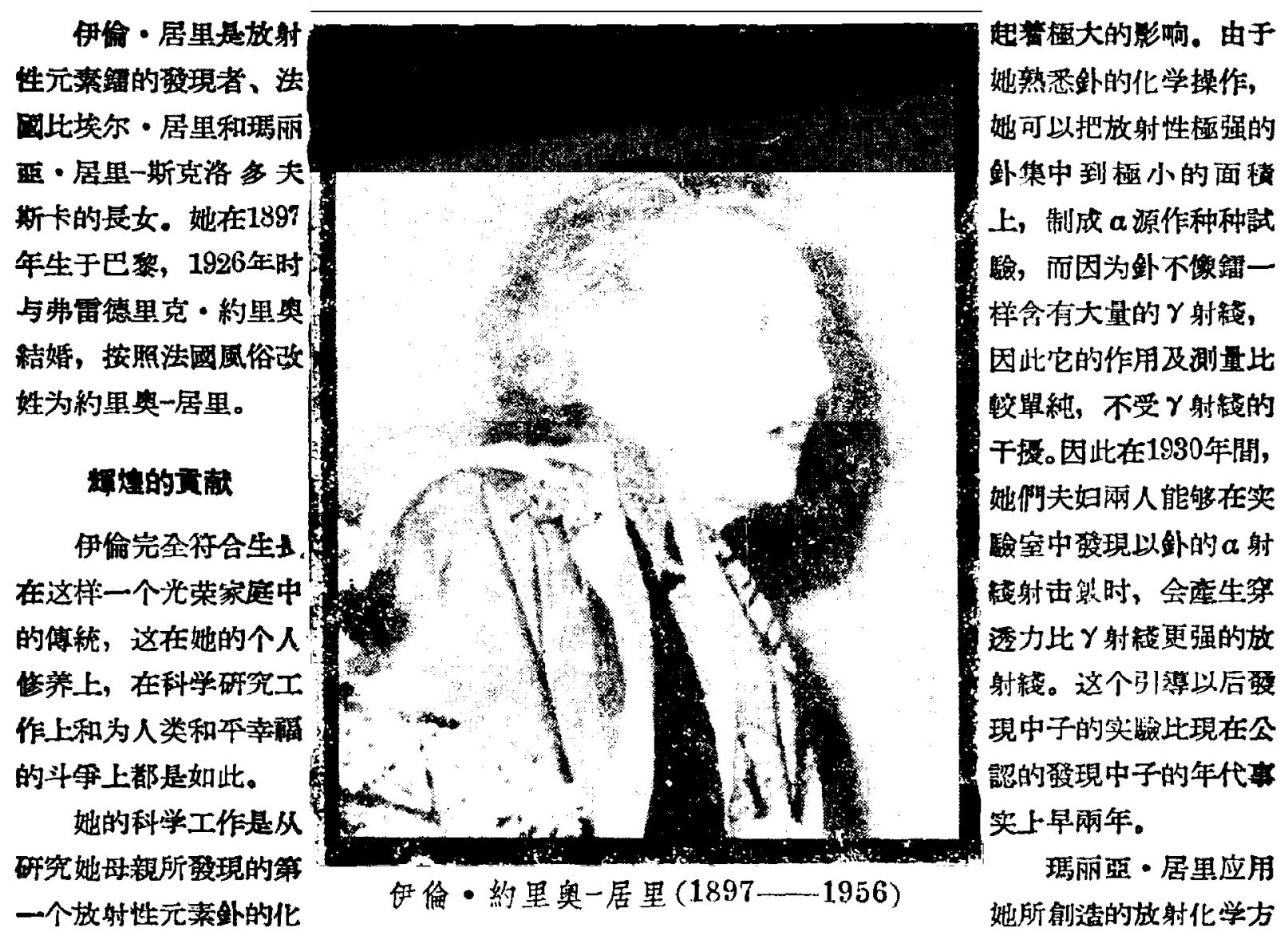

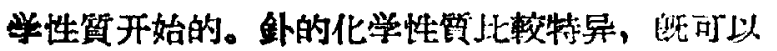

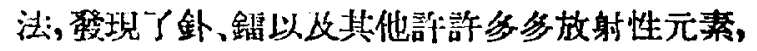
和金盛化合，又可以和非金篮化合，而目因为坐 廉期短, 得不到目所能見的量, 因此研究較难。

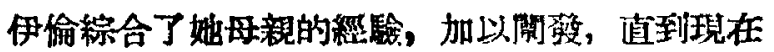
我們所了解的关于钋的化学性質, 还是㨽年前伊 偷所得到的䛍些結諭，几乎無所增改。

釙的化学性䆩的明了，对于伊倫以后的發現 开辟了整个原子核物理学。这方法在伊偷手里及

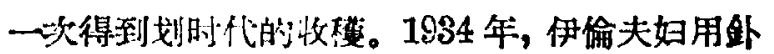

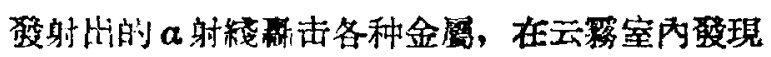

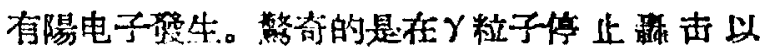

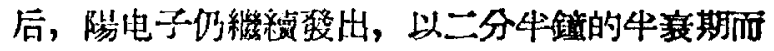
蚣变。伊倫以其丰富的想像力, 創造了一个非裳 
巧妙的放射化学方法，在極短的时間內把放射物 分离出來了，原來这是有放射性的磷，在白然 界本來是不存在的。这样她們首次以人工方法制 造了一种放射物，也發現了人造放射性的存在。

在第二次世界大战前夕, 意大利物理学家家費

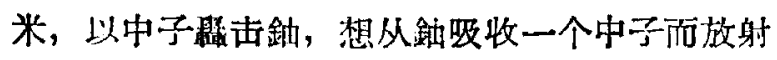
出 $\beta$ 射䌊的原子核反应中取獲超鈾元素。他以鎮 作載体獲得一些放射性以后，便錯鼠地以为是招 钢元素了。伊倫的化学天寸, 不久就以实驗証明, 指出这是铜。由于她的指証, 德國的化学家谈恩 再行仔細地試驗, 最后才肯定是釦与鉡, 从而㹻 現了叙的裂变性質，使原子能的解放成为汀能。

釙引涪了伊倫母女探害了原子核的構治，成 功地揭路了自然界的秘密使其造㵧于人类, 但不 幸的是这也損伤了伊倫的健康, 便得始的工作潧 到不可补偿的椇失。第二次大战期間，巴黎崄源，

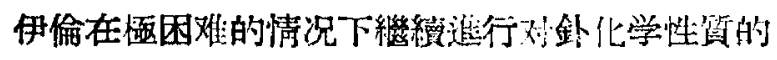
研究，出于意外，她和一位同等呼吸了釙化合物

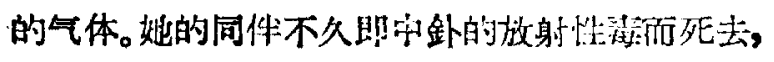

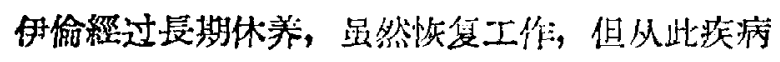
不断, 她的不尽其㨢, 与此题们关菜的。

\section{和平陣营中的坚强斗士}

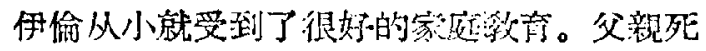

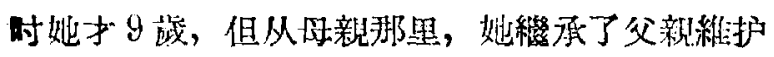
科学为人类幸楅服务的坚法的斗志。

在第一次揩界大战中，伊偷还是一个年整的

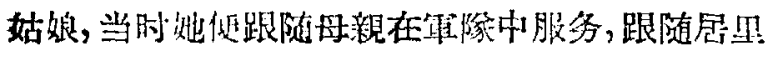

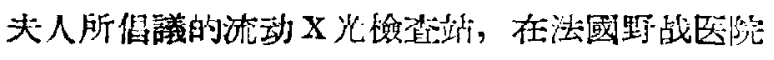

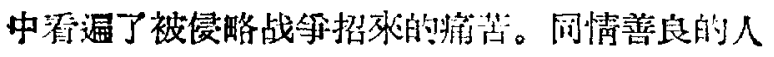

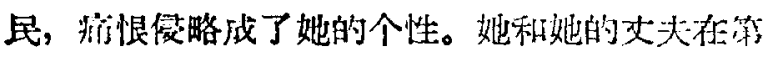

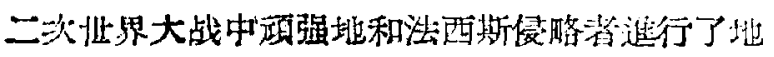
下斗筝。

对于親手㹲現的科学硼究成果, 她自然更有 权利望求为人类幸福服务了。在發現人造放射性 后接受諾貝尔獎金时，在对裂变作出貢献时，拉

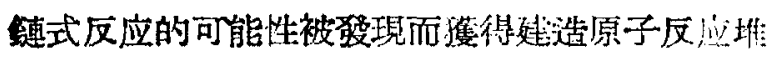
的專利权时, 她和丈夫都一再指出这种巨大的能 吾必須供和平应用, 絕不能相反地界于毁城人类。

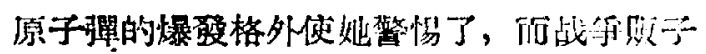

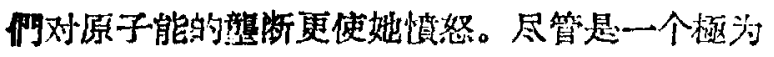

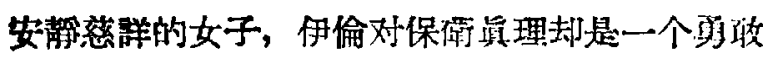

的斗土。她常說: I文对堭断原子能的最好办法, 便是自己作原子能的研究，赶上他們，超过他們。 1946年她利丈夫参加了法國原子能委員会，她日 以繼夜地工作，二年以后，英美集团以外的資本 主义图家中第一个反应堆, 以法國科学家自己的 力点造成了。

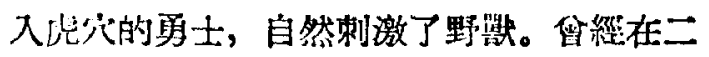
十几年前邀請居里夫人的美國妇联, 也邀請伊佮 赴美搹閏。但是美國的政府櫝加干涉, 借一个莫 須有的名义，把伊偷扣留在移民局的岛上，䋑过 全壮界科学家的紛粉抗議, 她被釋放了, 但仍然 沿有旮許入境。

印度科学院邀詿伊佮夫妇去訲問，当地的美 國咏啰們受到主子的指使，晹力阻止他們的活动， 倾徏他們不得不在几乎等于原定日程一牛的时間 內，提早絬束在印度的訪問旅行。

战争挑潑者和原子能壟断者对法國的爱國 者, 对法國科学家所作的最大的侮辱与迫害, 莫 如在 1950 年法國政付听从美國帝國主义者的命 分，把打倒英美原子能驡断权的法國原子能委員

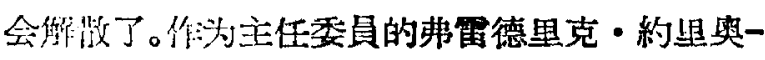

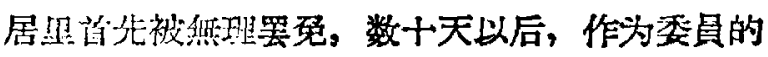
伊偷, 也被拒于她親手建立的为全法國以及全世 界科学家作出了巨大面献的法國原子能委員会阿 外了。

在这些年月星，伊㷍从未放奔她在巴黎大学 的㸚授㻍务，也始終浔有放奔她的研究生涯。

\section{实驗室大家㾔}

巴黎大学的㓡学研究所屈里实驗空, 自 1934

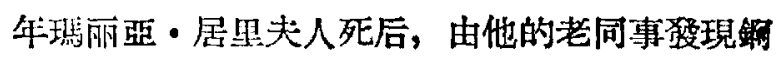
等激放射性元素的安・德比恩任主任。1946年 徳让恩告老退休，即由伊偷担任主任。凡是去过

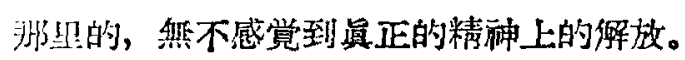

菬传歷史的实驗空, 那里集合了各种政治信 仰的人物，各和覤色的科学工作渚，潐行着物理 学与化学兩基本科学間分不明白的科学研究, 同 时也是融融洽洽的大家绽。那里常常些行社各种

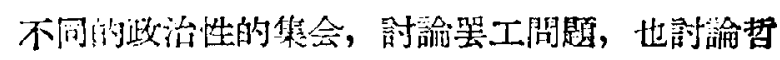

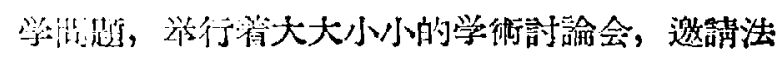
或的以及到巴黎冰的有名科学家來講演, 还不时

[下接96真] 